Fixed Point Theory, 21(2020), No. 2, 549-560

DOI: $10.24193 /$ fpt-ro.2020.2.39

http://www.math.ubbcluj.ro/ nodeacj/sfptcj.html

\title{
HALPERN TYPE ITERATION WITH TWO MAPPINGS IN A COMPLETE GEODESIC SPACE
}

\author{
HIROYUKI HIRONO* AND YASUNORI KIMURA** \\ * Department of Information Science, Toho University \\ Miyama, Funabashi, Chiba 274-8510, Japan \\ E-mail: 6519007h@st.toho-u.jp \\ ** Department of Information Science, Toho University \\ Miyama, Funabashi, Chiba 274-8510, Japan \\ E-mail: yasunori@is.sci.toho-u.ac.jp
}

\begin{abstract}
In this paper, we show a strong convergence theorem for the Halpern iteration procedure in a complete CAT(1) space with two quasinonexpansive $\Delta$-demiclosed mappings. We consider a sequence of coefficients for convex combination in the iterative scheme and find a certain discontinuity of the limit.
\end{abstract}

Key Words and Phrases: CAT(1) space, quasinonexpansive mapping, $\Delta$-demiclosed mapping, Halpern itaration.

2010 Mathematics Subject Classification: 47H09, 47H10.

\section{REFERENCES}

[1] K. Aoyama, Y. Kimura, F. Kohsaka, Strong convergence theorems for strongly relatively nonexpansive sequences and applications, J. Nonlinear Anal. Optim., Theory and Applications, 3(2012), 67-77.

[2] M.R. Bridson, A. Haefliger, Metric Spaces of Non-Positive Curvature, vol. 319 of "Grundlehren der. Mathematischen Wissenschaften", Springer, Verlag, Berlin, Germany, 1999.

[3] J.S. He, D.H. Fang, G. Lopez, C. Li, Mann's algorithm for nonexpansive mappings in CAT $(\kappa)$ spaces, Nonlinear Anal., 75(2012), 445-452.

[4] Y. Kimura, K. Satô, Halpern iteration for strongly quasinonexpansive mappings on a geodesic space with curvature bounded above by one, Fixed Point Theory Appl., 2013(2013), 14 pages.

[5] K. Nakagawa, Convergence Theorems to a Common Fixed Point of Two Mappings in CAT(1) spaces, Master Thesis, Toho University, 2015.

[6] S. Saejung, Halpern's iteration in CAT(0) spaces, Fixed Point Theory Appl., 2010 (2010), Art. ID 471781

[7] S. Saejung, P. Yotkaew, Approximation of zeros of inverse strongly monotone operators in Banach spaces, Nonlinear Anal., 75(2012), 742-750.

[8] R. Wittmann, Approximation of fixed points of nonexpansive mappings, Arch. Math. (Basel), 58(1992), 486-491.

Received: November 4, 2019; Accepted: January 11, 2020. 